\title{
Optimisation of the preparation of chemotherapy based on 5 -fluorouracil by the use of peristaltic pumps
}

https://doi.org/10.1515/PTHP-2020-0003

Received March 5, 2020; accepted May 14, 2020

\section{Abstract}

Objectives: Preparation of 5-FU elastomeric pumps is a time-consuming activity inducing musculoskeletal disorders (MSDs). Our unit has developed an automated filling system consisting of two peristaltic pumps (one for the diluent, one for the cytotoxic drug). The objective was to validate the accuracy of the assembly and evaluate the impact of automation on the compounding time, occurrence of MSDs and cost of preparation.

Methods: Accuracy was determined by calculating the total error on the volumes injected by the pumps. Measurements were made for 2 brands (AMF, Baxter), 3 different volumes; repeated 3 times at 3 times of the day. The time-saving study compared 24 measurements in manual filling and 24 in automated mode. Impact of automation on the occurrence of MSDs was evaluated by a self-assessment questionnaire. Finally, a comparison between the price of a manually prepared elastomeric pump and an automated prepared elastomeric pump was performed.

Results: Volumes administered by the pumps were accurate (total error $<2.5 \%$ ). Preparation time was divided by 2 . Occurrence of MSD decreased (8.7 manual filling vs. 23.5/ 28 automated filling). Overcost was moderate (14.7\% for AMF; $10.3 \%$ for Baxter).

Conclusions: Using peristaltic pumps, 5FU preparation was optimized for moderate additional cost.

Keywords: automation; chemotherapies; elastomeric pumps; musculo-skeletal disorders; peristaltic pumps.

*Corresponding author: Alexandre Villain, Centre Oscar Lambret, Pharmacy, 3 rue Combemale, 59020 Lille cedex, Lille, France, Phone: +33 (0) 320295906, Fax: +33 (0) 20295978,

E-mail: a-villain@o-lambret.fr

Ilyes Sakji, Geoffrey Strobbe, Guillaume Marliot and Frédéric Feutry: Centre Oscar Lambret, Pharmacy, Lille, France

Emilie Bogart: Centre Oscar Lambret, Methodology and Biostatistic Unit, Lille, France

\section{Introduction}

Anticancer treatments present a risk both for the personnel who prepare the treatment by handling cytotoxic drugs and for the treated patient in case of preparation errors [1-8].

The risk of error is all the greater as the number of anticancer preparations increases from year to year and the preparations must be carried out faster, which also increases the mechanical stress and chemical contamination risk of the manipulators.

Portable elastomeric pumps with different volume reservoirs and that operate at different flow rates are marketed, adaptable to each patient's therapy needs (different doses and administration times) [9]. An elastomeric pump also enables the administration of chemotherapy in the outpatient setting, reducing both patients' length of stay and the workload of nurses and pharmacists. In addition, no manipulation is required after connection to the patient, reducing the risk of subsequent contamination.

One of the disadvantages of elastomeric pumps is the variability of the infusion flow rate. This rate varies depending on several factors including temperature, viscosity, and height of the reservoir and the Luer lock connector [10]. Medicines with a narrow therapeutic range should not be administered with an elastomeric pump because of the inaccuracy of the system. Moreover, the administration of drugs requiring patient monitoring cannot be done via such a pump. This does not pose a problem for the administration of 5-fluorouracil (5-FU) [9].

Additional important disadvantages include the preparation time of the elastomeric pumps [11] and the occurrence of musculo-skeletal disorders (MSD) [12]. Indeed, the preparation of cytotoxic drugs involves the permanent and sustained use of the upper limbs, fingers and upper body. When filling the elastomeric pump, an additional effort from users is required to oppose the resistance of the elastomeric membrane, which increases even more the risk of occurrence of MSD [13].

To the present day, cancer treatment activity continues to grow. Pharmacists have to prepare more and 
more chemotherapies $(10 \%$ increase in 5 years in our center), without delay (less than $1 \mathrm{~h}$ according to national recommendations) to ensure the best patient satisfaction. In this context, automated systems have been shown to optimise the preparation time (several dozen chemotherapies an hour) improving the ergonomics of the work of hospital pharmacy technicians [13-16]. In the other hand, automated system installation is usually very expensive (several hundred thousand euros just for the robot).

That's why,in our center and with a view to optimising preparation time and improving the ergonomics of the work of hospital pharmacy assistants while keeping a lid on costs, we designed in Oscar Lambret Center, an automated filling system containing two Repeater ${ }^{\circledR}$ pumps for the infusion of 5-FU.

The first objective of the present study was to validate the automated filling system by evaluating the accuracy of volumes administered. The second objective was to evaluate the impact of automation on the preparation time and the risk of MSD (musculoskeletal disorders). The third objective was to assess the economic cost of the new device.

\section{Materials and methods}

\section{The filling system}

The assembly studied is presented in Figure 1. The two Repeater ${ }^{\circledR}$ peristaltic pumps (Baxter; ref: H938099E) are connected to the 5-FU and diluent (3,000 $\mathrm{mL} \mathrm{0.9 \%} \mathrm{NaCl}$ Aguettant, ref: 5620730) reservoir bags through a transfer tubing (Baxter; ref: H93833). The other end of the tubing is connected to the elastomeric pump through a Y connector (ICU; ref: 011-MC33128) and a Spiros ${ }^{\circledR}$ (ICU; ref: CH2000S-PC) luer [17].

The 5-FU bag was prepared from 10 vials of 5-FU (ACCORD; $5,000 \mathrm{mg} / 100 \mathrm{~mL}$ ) filled into an empty bag (MACOPHARMA; ref: PB10005122T20CPP075). The amount of 5-FU is intended to contain enough cytotoxic drug to prepare all elastomeric pumps of the day.

Peristaltic pumps are intended for use in isolators. The dimensions of a pump are $20.5 \times 28 \times 24.5 \mathrm{~cm}$. A working space of about $90 \mathrm{~cm}$ is required for the installation and use of the pumps. Our isolators are sized to accommodate these two pumps.

Six different elastomeric pumps were studied:

- FOLFusor® LV 2 (BAXTER, ref: 2C4008K)

- FOLFusor ${ }^{\circledR}$ LV 5 (BAXTER, ref: 2C4009K)

- FOLFusor ${ }^{\circledR}$ LV 10 (BAXTER, ref: 2C4036K)

- AutoFuser® $2.5 \mathrm{~mL} / \mathrm{h}$ (AMF, ref: AA2011-1-S)

- AutoFuser ${ }^{\circledR} 4 \mathrm{~mL} / \mathrm{h}$ (AMF, ref: AA2004-1-S)

- AutoFuser 10 mL/h (AMF, ref: AA2010-1)

\section{Calibration of the peristaltic pumps}

A daily calibration of the two pumps was performed by infusing $40 \mathrm{~mL}$ of $0.9 \% \mathrm{NaCl}$ in $60 \mathrm{~mL}$ syringes (BD: ref 300865). For practical reasons

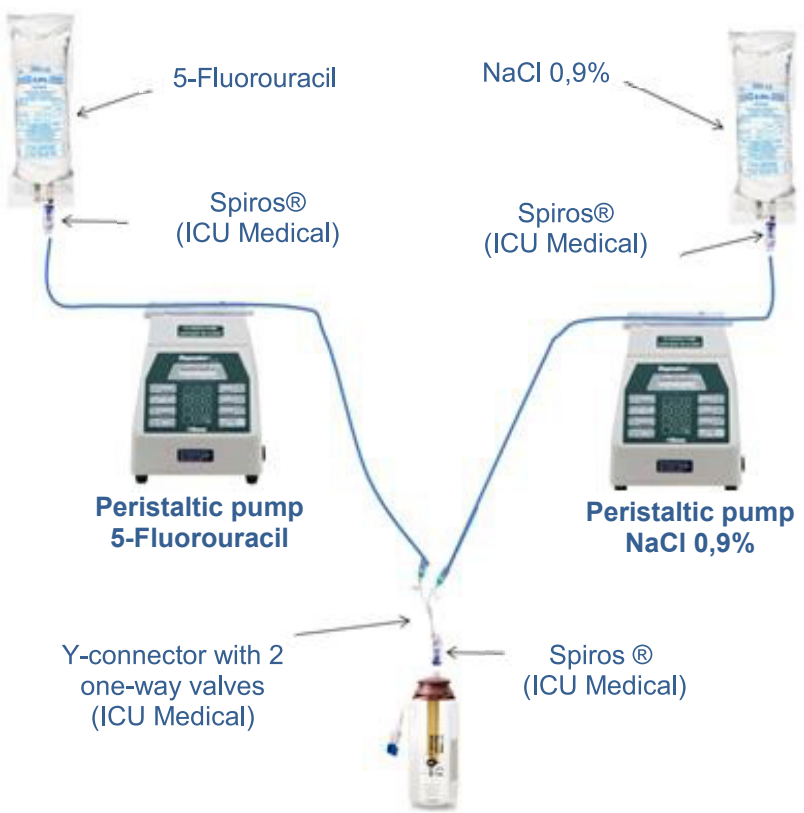

Figure 1: The studied assembly.

and in order not to impact the production of chemotherapy for patients, calibration and measurements were performed outside of the controlled-atmosphere area by replacing the 5 -FU with $0.9 \% \mathrm{NaCl}$, which has a similar density and viscosity. The adjustment between the $0.9 \% \mathrm{NaCl}$ volumes theoretically injected by the Repeater ${ }^{\circledR}$ pumps and the volumes actually injected was done by reading the syringes. The speed of the pumps chosen for this study, "Medium 5", was that intended for routine use.

\section{Accuracy of the volumes delivered by the pumps}

After calibration, the accuracy of the volumes delivered by the pumps was measured using the gravimetric method. Volumes were weighted with a Mettler Toledo® precision-controlled balance (MS3002 TS/M ref: 30133561). The weight of the diluent actually delivered by the pump was compared with the weight of the volume theoretically delivered.

The measurements were performed on the six elastomeric pumps. For each of them, the measurements were made on three different volumes, repeated three times at three times of the day (at start, middle and end of production). So, nine measurements for one elastomeric pump and one volume were done.

For Baxter pumps, with a nominal volume of $240 \mathrm{~mL}$, the volumes of 5-FU studied were $10 \mathrm{~mL}$ ( $+230 \mathrm{~mL}$ of diluent), $120 \mathrm{~mL}$ ( $+120 \mathrm{~mL}$ of diluent) and $230 \mathrm{~mL}$ ( $+10 \mathrm{~mL}$ of diluent).

For AMF pumps, with a nominal volume of $275 \mathrm{~mL}$, the volumes of 5-FU studied were $10 \mathrm{~mL}$ ( $+265 \mathrm{~mL}$ of diluent), $137 \mathrm{~mL}$ ( $+138 \mathrm{~mL}$ of diluent) and $265 \mathrm{~mL}$ (+10 $\mathrm{mL}$ of diluent)

The accuracy of the volumes delivered by the two pumps was calculated and expressed as the total error in percent (sum of accuracy/bias and precision/trueness) as described for the validation of quantitative analytical procedure. 


\section{Objective 2.1: optimisation of the preparation time}

This part of the study involved 48 time measurements. Six different pharmacy technicians filled the FOLFusor ${ }^{\circledR}$ LV 5 and the AutoFuser ${ }^{\circledR}$ $4 \mathrm{~mL} / \mathrm{h}$, automatically and manually, and each measurement was repeated twice.

For this study, $80 \mathrm{~mL}$ of 5-FU for $150 \mathrm{~mL}$ of diluent were used, which represents the average volume of most reconstituted elastomeric pumps used in our center.

The steps for the manual and automated preparation processes of the filling systems are detailed in Table 1: and 2:, respectively.

In order to determine the time gained by the use of pumps, the median and mean filling times for automatic vs. manual filling were described and a statistical analysis (Student's test) between the two was performed.

To ensure that the type of elastomeric pump and the user chosen for the study did not have any impact on the results, a statistical analysis (Wilcoxon Mann-Whitney test) on the filling time with Baxter vs. AMF pumps and a statistical analysis (Wilcoxon Mann-Whitney test) on the filling time according to the pharmacy technician were performed.

\section{Objective 2.2: decrease of MSD}

The occurrence of MSD was measured with a self-questionnaire. Each of the six pharmacy technicians filled the questionnaire for each of the 2 elastomeric pumps both for an automated and for a manual filling (24 in total).

The questionnaire is based on the OSHA (Occupational Safety and Health Administration) checklist used by the American institute NIOSH (Health National Institute for occupational Safety and Health) for the detection of work situations likely to be at risk for upper limb MSD.

This checklist is divided into seven items: repetitiveness, manual effort, awkward postures, skin pressure, vibration, work environment and control of the work pace. These items are themselves subdivided into items that are scored individually [18].

In this study, the questionnaire was adapted to the preparation of the filling system and the following items were selected: repetitiveness, manual effort, awkward postures (divided into 5 sub-items) and skin pressure. The pharmacy technicians scored each item according to the intensity. The higher the score, the more intense the criterion studied. All individual scores were then summed to obtain a total score ranging from 0 to 28 (Figure 2).

The Wilcoxon Mann Whitney Test for paired data was applied to each question to test the difference between automatic and manual filling.

\section{Objective 3: economic cost}

The final part of the study compared the production price of a manual filling system with that of an automated system. The production costs of a manual and automated preparation were calculated considering the material used for each system. In a second step, the price of assembly was calculated and integrated into the price of automated preparations. The preparation price according to the number of preparations was represented in a graphic in order to estimate the price of the assembly taking into account the number of daily preparations.
Table 1: Steps necessary for the preparation of the elastomeric pump without the use of peristaltic pumps.

\begin{tabular}{|c|c|}
\hline Step 1 & $\begin{array}{l}\text { Control of vials: Scan of the 5-FU vials identification } \\
\text { DataMatrix bar code }\end{array}$ \\
\hline Step 2 & $\begin{array}{l}\text { Elastomeric pump control: Scan of the pump } \\
\text { DataMatrix bar code }\end{array}$ \\
\hline Step 3 & Weight of the elastomeric pump \\
\hline Step 4 & Weight of the empty syringe \\
\hline Step 5 & Collection of the $50-\mathrm{mL}$ of $\mathrm{NaCl} 0.9 \%$ bag \\
\hline Step 6 & Weight of the syringe + volume of $\mathrm{NaCl} 0.9 \%$ \\
\hline Step 7 & Injection of the diluent into the elastomeric pump \\
\hline Step 8 & Collection of the $50-\mathrm{mL}$ of $\mathrm{NaCl} 0.9 \%$ bag \\
\hline Step 9 & Weight the syringe + volume of $\mathrm{NaCl} 0.9 \%$ \\
\hline Step 10 & Injection of the diluent into the elastomeric pump \\
\hline Step 11 & Collection of the $50-\mathrm{mL}$ of $\mathrm{NaCl} 0.9 \%$ bag \\
\hline Step 12 & Weight of the syringe + volume of $\mathrm{NaCl} 0.9 \%$ \\
\hline Step 13 & Injection of the diluent into the elastomeric pump \\
\hline Step 14 & Weight of the elastomeric pump with the diluent \\
\hline Step 15 & Weight of the empty syringe \\
\hline Step 16 & Collection of $40 \mathrm{~mL}$ of 5 -FU \\
\hline Step 17 & Weight of the syringe +5 -FU \\
\hline Step 18 & Injection of the 5-FU into the elastomeric pump \\
\hline Step 19 & Collection of $40 \mathrm{~mL}$ of $5-\mathrm{FU}$ \\
\hline Step 20 & Weight of the syringe $+5-\mathrm{FU}$ \\
\hline Step 21 & Injection of the 5-FU into the elastomeric pump \\
\hline Step 22 & Final weight of the elastomeric pump \\
\hline Step 23 & Labeling of the preparation \\
\hline
\end{tabular}

\section{Results}

\section{Accuracy of the volumes delivered by the peristaltic pumps}

The results obtained for the two pumps and for each type of elastomeric pump are presented in Table 3.

For all measurements, the total error was less than $2.5 \%$. For all the volumes studied, the measurements were accurate with a bias ranging between -0.90 and $1.61 \%$.

Table 2: Steps necessary for the automated preparation of the elastomeric pump.

\begin{tabular}{ll}
\hline Step 1 & $\begin{array}{l}\text { Elastomeric pump control: Scan of the pump } \\
\text { DataMatrix bar code } \\
\text { Weight of the elastomeric pump } \\
\text { Step 2 }\end{array}$ \\
Step 3 & $\begin{array}{l}\text { Weight of the diluent bag } \\
\text { Injection of } 150 \mathrm{~mL} \text { of diluent }\end{array}$ \\
Step 4 & Bag control: Scan of the 5-FU bag Identification \\
Step 5 & DataMatrix bar code \\
Injection of $80 \mathrm{~mL}$ of 5-FU into the elastomeric pump \\
Step 6 & Weight of the diluent bag \\
Step 7 & Final weight of the elastomeric pump \\
Step 8 & Labelling of the preparation \\
Step 9 &
\end{tabular}




\begin{tabular}{|c|c|c|c|}
\hline Items & Manual & Automated & $\begin{array}{l}\text { Maximum } \\
\text { score }\end{array}$ \\
\hline 11: Repetitiveness & & & 17 \\
\hline 12: Manual effort & & & $/ 6$ \\
\hline \multicolumn{4}{|l|}{ Awkward postures } \\
\hline 13: Neck: rotation/flexion & & & 12 \\
\hline $\begin{array}{l}\text { 14: Shoulders: upper limb without support or } \\
\text { elbow higher than the middle of the chest }\end{array}$ & & & 13 \\
\hline 15: Rapid movement of the fore-arm & & & 12 \\
\hline 16: Wrist: flexion/extension & & & 13 \\
\hline 17: Fingers & & & $/ 1$ \\
\hline 18: Skin pressure & & & 14 \\
\hline Total score & & & 128 \\
\hline
\end{tabular}

Figure 2: Self-evaluation questionnaire.

The precision error between the measurements was low, ranging from 0.11 to $1.60 \%$ for all results. The repetition of measurements over time had little or no influence on the accuracy of the infusion volumes.

In addition, the accuracy of pump A (precision between 0.11 and 1.24\%) and pump B (precision between 0.19 and $1.60 \%$ ) for both elastomeric pumps was the same.

For all the volumes measured using the Baxter pumps, the total error ranged between 0.34 and $1.62 \%$ with a bias between -0.72 and $0.73 \%$ and a precision error between 0.14 and $1.06 \%$.

For all the volumes measured using the AMF pumps, the total error ranged between 0.52 and $2.42 \%$ with a bias between -0.90 and $1.61 \%$ and a precision error between 0.11 and $1.60 \%$.

\section{Results of objective 2.1: automatic vs. manual filling times}

Mean (SD) time for automatic filling was 156.8 (15.2) seconds vs. 301.5 (15.7) seconds when done manually (student test: $\mathrm{p}<0.001)$.

\section{Filling time depending on the type of elastomeric pump}

The filling time difference was not statistically significant between the two elastomeric pump types, neither globally nor depending on manual/automatic filling $(p=0.089$, Wilcoxon Mann-Whitney test) (Table 4).

\section{Filling time depending on pharmacy technicians}

The filling time was not significantly different between the six pharmacy technicians ( $p=0.895$, Wilcoxon MannWhitney test) (Table 5).

Table 3: Accuracy of the volumes administered by the pumps (each values of accuracy, precision and total error are based on the results of the nine repetitions ( 3 times at start, middle and end of production).

\begin{tabular}{|c|c|c|c|c|c|c|c|c|c|}
\hline & & \multicolumn{4}{|c|}{ PUMP A (5FU) } & \multicolumn{4}{|c|}{ PUMP B (Diluent) } \\
\hline & & $\begin{array}{r}\text { Theoretical } \\
\text { volume }(\mathrm{mL})\end{array}$ & $\begin{array}{l}\text { Accuracy } \\
\text { (bias) (\%) }\end{array}$ & $\begin{array}{r}\text { Precision } \\
\text { (trueness) (\%) }\end{array}$ & $\begin{array}{r}\text { Total } \\
\text { error (\%) }\end{array}$ & $\begin{array}{r}\text { Theoretical } \\
\text { volume }^{\star}(\mathrm{mL})\end{array}$ & $\begin{array}{r}\text { Accuracy } \\
\text { (bias) (\%) }\end{array}$ & $\begin{array}{r}\text { Precision } \\
\text { (trueness) (\%) }\end{array}$ & Total error (\%) \\
\hline \multirow[t]{9}{*}{ BAXTER } & $10 \mathrm{~mL} / \mathrm{h}$ & 10 & 0.44 & 0.54 & 0.99 & 230 & 0.05 & 0.29 & 0.34 \\
\hline & & 120 & 0.64 & 0.50 & 1.14 & 120 & 0.19 & 0.39 & 0.59 \\
\hline & & 230 & 0.35 & 0.34 & 0.69 & 10 & -0.33 & 0.75 & 1.08 \\
\hline & $5 \mathrm{~mL} / \mathrm{h}$ & 10 & -0.56 & 1.06 & 1.62 & 230 & -0.72 & 0.82 & 1.54 \\
\hline & & 120 & -0.25 & 0.24 & 0.49 & 120 & -0.64 & 0.90 & 1.54 \\
\hline & & 230 & -0.26 & 0.14 & 0.40 & 10 & 0.00 & 0.96 & 0.96 \\
\hline & $2 \mathrm{~mL} / \mathrm{h}$ & 10 & 0.11 & 1.00 & 1.11 & 230 & 0.14 & 0.59 & 0.73 \\
\hline & & 120 & 0.52 & 0.23 & 0.75 & 120 & 0.51 & 0.38 & 0.89 \\
\hline & & 230 & 0.73 & 0.50 & 1.23 & 10 & 0.33 & 1.01 & 1.35 \\
\hline \multirow[t]{9}{*}{ AMF } & $10 \mathrm{~mL} / \mathrm{h}$ & 10 & 0.00 & 1.12 & 1.12 & 265 & -0.42 & 1.60 & 2.02 \\
\hline & & 137 & 0.42 & 0.69 & 1.11 & 138 & -0.90 & 1.52 & 2.42 \\
\hline & & 265 & 0.43 & 0.30 & 0.73 & 10 & 0.11 & 1.28 & 1.39 \\
\hline & $4 \mathrm{~mL} / \mathrm{h}$ & 10 & 1.33 & 0.87 & 2.20 & 265 & 1.03 & 0.49 & 1.52 \\
\hline & & 137 & 1.31 & 0.36 & 1.66 & 138 & 1.23 & 0.19 & 1.43 \\
\hline & & 265 & 1.61 & 0.11 & 1.71 & 10 & 0.67 & 0.74 & 1.41 \\
\hline & $2.5 \mathrm{~mL} / \mathrm{h}$ & 10 & 0.62 & 1.24 & 1.91 & 265 & -0.19 & 0.47 & 0.66 \\
\hline & & 137 & 0.79 & 0.41 & 1.20 & 138 & 0.23 & 0.30 & 0.52 \\
\hline & & 265 & 0.01 & 0.70 & 0.70 & 10 & 0.67 & 0.74 & 1.41 \\
\hline
\end{tabular}

*Complementary volume to pump A (pump containing 5-FU). 
Table 4: Automatic and manual filling times for AMF and Baxter elastomeric pumps.

\begin{tabular}{lllr}
\hline & Time (s) & & $\mathbf{p}$ \\
\cline { 2 - 3 } & AMF pump & Baxter pump & \\
\hline Automatic & $\mathrm{n}=12$ & $\mathrm{n}=12$ & 0.089 \\
Median (range) & $149(138-172)$ & $158.5(131-183)$ & (Wilcoxon) \\
Mean (SD) & $152.5(12.9)$ & $161.2(16.6)$ & \\
Manual & $\mathrm{n}=12$ & $\mathrm{n}=12$ & \\
Median (range) & $291(277-316)$ & $310(296-338)$ & \\
Mean (SD) & $291.8(11.9)$ & $311.2(12.9)$ & \\
\hline
\end{tabular}

\section{Objective 2.2: decrease of MSD}

Table 6 presents the scores obtained for each question for the automatic or manual filling and overall. A total mean (SD) score of 23.5 (2.8) was obtained for manual preparations vs. 8.7 (4.5) for automated preparations. For all except for question 3 (neck rotation/flexion), there was a significantly lower score (lower risk of MSDs) for automatic filling compared with manual filling.

\section{Objective 3: economic cost}

Considering the material used, the manufacturing cost of a manual elastomeric pump is $23.72 €$ (all taxes included) with a Baxter pump and $16.52 €$ (all taxes included) with an AMF pump (Table 7).

The cost of an automated preparation includes the price of the peristaltic pump, the price of the assembly and the material necessary for the calibration of pumps, smoothed out with regard to the number of preparations per day. Considering that Baxter Repeater ${ }^{\circledR}$ pumps have an estimated life expectancy of 7 years, the annual cost for both pumps would be of $1964.69 €$ (all taxes included). Considering an approximate number of working days of
250 , the price of the pumps for a working day is estimated at $7.86 €$ (all taxes included). For a day of activity, the price of assembly and calibration is $75.56 €$ (all taxes included), leading to a total cost of $83.42 €$ (all taxes included) (Table 8).

The cost difference for the preparation of an elastomeric pump using either Baxter or AMF peristaltic pumps between the automatic and manual systems was $70.44 €$ (all taxes included).

Considering that the daily assembly will be used 10 times, the total cost of Baxter elastomeric pumps is $261.6 €$ (all taxes included) for the automatic system and $237.2 €$ (all taxes included) for the manual system. Similarly, the total cost for the preparation of 10 automated and manual AMF elastomeric pumps is of $189.56 €$ (all taxes included) and $165.20 €$ (all taxes included), respectively. The difference in cost between automatic system and manual system for both AMF and Baxter elastomeric pumps is the same: $2.44 €$ (all taxes included) for one preparation.

The cost of assembly is smoothed out by the 10 preparations thus reducing the additional cost of an automated preparation. The price of the automated preparation of an elastomeric pump using AMF pumps was estimated at 18.96 $€$ (including all taxes) (15\% increase compared to manual preparation) and $26.16 €$ (including all taxes) for a Baxter broadcaster (10\% increase over manual preparation).

The cost of an automatic Baxter or AMF elastomeric pump is lower than that of a manual system for 19 preparations or over.

\section{Discussion}

This study demonstrates that the assembly developed in our center allows optimising the preparation of 5-FU elastomeric pumps without reducing the level of safety of the product and of the personnel.

Table 5: Automatic and manual filling times depending on the pharmacy technician.

\begin{tabular}{lllllll}
\hline & Time (s) & & & & \\
\cline { 2 - 7 } & $\begin{array}{l}\text { Pharmacy } \\
\text { technician 1 }\end{array}$ & $\begin{array}{l}\text { Pharmacy } \\
\text { technician 2 }\end{array}$ & $\begin{array}{l}\text { Pharmacy } \\
\text { technician 3 }\end{array}$ & $\begin{array}{l}\text { Pharmacy } \\
\text { technician 4 }\end{array}$ & $\begin{array}{l}\text { Pharmacy } \\
\text { technician 5 }\end{array}$ & $\begin{array}{l}\text { Pharmacy } \\
\text { technician 6 }\end{array}$ \\
\hline Automatic & $\mathrm{n}=4$ & $\mathrm{n}=4$ & $\mathrm{n}=4$ & $\mathrm{n}=4$ & $\mathrm{n}=4$ & $\mathrm{n}=4$ \\
Median (range) & $158(140-181)$ & $159.5(146-176)$ & $143.5(131-155)$ & $159.5(144-183)$ & $153(139-176)$ & $165.5(142-173)$ \\
Mean (SD) & $159.3(20.3)$ & $160.3(13.4)$ & $143.3(10.8)$ & $161.5(17.5)$ & $155.3(15.3)$ & $161.5(13.6)$ \\
Manual & $\mathrm{n}=4$ & $\mathrm{n}=4$ & $\mathrm{n}=4$ & $\mathrm{n}=4$ & $\mathrm{n}=4$ & $\mathrm{n}=4$ \\
Median (range) & $294.5(277-338)$ & $303.5(291-310)$ & $289.5(277-311)$ & $306.5(293-323)$ & $297(284-321)$ & $310.5(287-321)$ \\
Mean (SD) & $301(26.2)$ & $302(9.1)$ & $291.8(15.1)$ & $307.3(14.1)$ & $299.8(15.5)$ & $307.3(15.1)$ \\
\hline
\end{tabular}


Table 6: Questionnaire scores for automatic and manual fillings and overall.

\begin{tabular}{|c|c|c|c|c|}
\hline Questionnaire MSD items & Automatic $(n=12)$ & Manual $(n=12)$ & Total $(n=24)$ & p (Wilcoxon test) \\
\hline I1: Repetitiveness & & & & 0.002 \\
\hline Median (range) & $2(1-6)$ & $6(5-7)$ & $5.5(1-7)$ & \\
\hline Mean (SD) & $3(1.7)$ & $6.3(0.6)$ & $4.6(2.1)$ & \\
\hline 12: Manual effort & & & & 0.002 \\
\hline Median (range) & $2(0-4)$ & $5(4-6)$ & $4(0-6)$ & \\
\hline Mean (SD) & $1.6(1.1)$ & $5.3(0.7)$ & $3.5(2.1)$ & \\
\hline 13: Neck: rotation/flexion & & & & 0.343 \\
\hline Median (range) & $1(0-2)$ & $1(0-2)$ & $1(0-2)$ & \\
\hline Mean (SD) & $0.7(0.7)$ & $0.9(0.8)$ & $0.8(0.7)$ & \\
\hline 14: Shoulders & & & & 0.002 \\
\hline Median (range) & $1(1-2)$ & $2.5(2-3)$ & $2(1-3)$ & \\
\hline Mean (SD) & $1.2(0.4)$ & $2.5(0.5)$ & $1.8(0.8)$ & \\
\hline 15: Rapid movement of the fore-arm & & & & 0.03 \\
\hline Median (range) & $0.5(0-2)$ & $1.5(0-2)$ & $1(0-2)$ & \\
\hline Mean (SD) & $0.6(0.7)$ & $1.4(0.7)$ & $1(0.8)$ & \\
\hline 16: Wrist: flexion/extension & & & & 0.002 \\
\hline Median (range) & $1(0-2)$ & $3(2-3)$ & $2(0-3)$ & \\
\hline Mean (SD) & $1(0.6)$ & $2.7(0.5)$ & $1.8(1)$ & \\
\hline I7: Fingers & & & & 0.002 \\
\hline Median (range) & $0(0-1)$ & $1(1-1)$ & $1(0-1)$ & \\
\hline Mean (SD) & $0.2(0.3)$ & $1(0)$ & $0.6(0.5)$ & \\
\hline 18: Skin overpressure & & & & 0.002 \\
\hline Median (range) & $0(0-2)$ & $3.5(2-4)$ & $2(0-4)$ & \\
\hline Mean (SD) & $0.5(0.7)$ & $3.4(0.7)$ & $2(1.6)$ & \\
\hline Total & & & & 0.002 \\
\hline Median (range) & $8(3-18.5)$ & $23(20-28)$ & $19.3(3-28)$ & \\
\hline Mean (SD) & $8.7(4.5)$ & $23.5(2.8)$ & $16.1(8.4)$ & \\
\hline
\end{tabular}

Table 7: Materials used for manual preparation of elastomeric pump.

\begin{tabular}{|c|c|c|c|c|c|}
\hline Materials & Provider & Reference number & $\begin{array}{r}\text { Unit Price } \\
\text { (tax included) }\end{array}$ & Quantity & $\begin{array}{r}\text { Total Price } \\
\text { (tax included) }\end{array}$ \\
\hline \multirow[t]{2}{*}{ Elastomeric pump } & BAXTER & $\begin{array}{l}\text { FOLFusor }{ }^{\circledR} \text { LV2: } 2 \text { C } 4008 \mathrm{~K}, \\
\text { FOLFusor }{ }^{\circledR} \text { LV5: } 2 \text { C } 4009 \mathrm{~K}, \\
\text { FOLFusor }{ }^{\circledR} \text { LV10: } 2 \text { C4063K }\end{array}$ & 18.6 euros & 1 & 18.6 euros \\
\hline & AMF & $\begin{array}{c}\text { AutoFuser }{ }^{\circledR} 2.5 \mathrm{~mL} / \mathrm{h} \text { AA2011-1-S, } \\
\text { AutoFuser }{ }^{\circledR} 4 \mathrm{~mL} / \mathrm{h} \text { AA2004-1-S, } \\
\text { AutoFuser }{ }^{\circledR} 10 \mathrm{~mL} / \mathrm{h} \text { AA2010-1 }\end{array}$ & 11.40 euros & 1 & 11.40 euros \\
\hline Spiros $®$ & ICU & CH2000S-PC & 1.74 euros & 3 & 5.22 euros \\
\hline Take Set $\circledast$ & CODAN & 16.4200 & 1.16 euros & 1 & 1.16 euros \\
\hline $\begin{array}{l}\text { Bag of sodium chloride } \\
\text { solution }(250 \mathrm{~mL}) \text { EASYFLEX }+\end{array}$ & MACOPHARMA & ACG0419FR & 0.69 euros & 2 & 0.69 euros \\
\hline Syringe $(60 \mathrm{~mL})$ & $\mathrm{BD}$ & 300865 & 0.22 euros & 2 & 0.44 euros \\
\hline Spike ${ }^{\circledR}$ & ICU & $\mathrm{CH}-70$ & 1.31 euros & 10 & 13.1 euros \\
\hline
\end{tabular}

We developed a filling system consisting of two Repeater ${ }^{\circledR}$ peristaltic pumps. Although several studies have shown the benefits of automated preparations with the help of pumps [15, 19-23], there are no reports on the use of a two-pump assembly injecting the diluent and then the 5-FU without prior disconnection of the pump.
The analysis validated the accuracy of the volumes administered by the pumps on a day of activity (total error of less than 2.5\%) and thus our assembly for the Baxter and AMF filling system preparation.

These results are consistent with those of Humbert et al. [19]; who studied the accuracy of the volumes 
Table 8: Materials used for automated preparation of elastomeric pump.

\begin{tabular}{|c|c|c|c|c|c|}
\hline Materials & Provider & Reference number & $\begin{array}{r}\text { Unit Price } \\
\text { (tax included) }\end{array}$ & Quantity & $\begin{array}{r}\text { Total Price } \\
\text { (tax included) }\end{array}$ \\
\hline \multicolumn{6}{|l|}{ Elastomeric pump } \\
\hline & BAXTER & $\begin{array}{l}\text { FOLFusor }{ }^{\circledR} \text { LV2: } 2 \text { C } 4008 \mathrm{~K}, \\
\text { FOLFusor }{ }^{\circledR} \text { LV5: } 2 \text { C4009K, } \\
\text { FOLFusor }{ }^{\circ} \text { LV10: } 2 \text { C4063K }\end{array}$ & 18.6 euros & 1 & 18.6 euros \\
\hline & AMF & $\begin{array}{c}\text { AutoFuser }{ }^{\circledR} 2.5 \mathrm{~mL} / \mathrm{h} \text { AA2011-1-S, } \\
\text { AutoFuser }{ }^{\circledR} \mathrm{mL} / \mathrm{h} \text { AA2004-1-S, } \\
\text { AutoFuser }{ }^{\circledR} 10 \mathrm{~mL} / \mathrm{h} \text { AA2010-1 }\end{array}$ & 11.40 euros & 1 & 11.40 euros \\
\hline \multicolumn{6}{|l|}{ Assembly } \\
\hline $\begin{array}{l}\text { Peristaltic pump } \\
\text { (Repeater } \circledast)\end{array}$ & BAXTER & H938099E & 6876.43 euros & 2 & 13752.86 euros \\
\hline Transfer tubing & BAXTER & H938331 & 18 euros & 2 & 36 euros \\
\hline Y-connector & ICU & 011-MC33128 & 1.548 euros & 1 & 1.548 euros \\
\hline Spiros $®$ & ICU & CH2000S-PC & 1.74 euros & 3 & 5.22 euros \\
\hline Take Set $®$ & CODAN & 16.4200 & 1.16 euros & 1 & 1.16 euros \\
\hline Empty bag (1 L) & MACOPHARMA & PB10005122T20СРP075 & 4.68 euros & 1 & 4.68 euros \\
\hline $\begin{array}{l}\text { Bag of sodium } \\
\text { chloride solution (1 L) }\end{array}$ & FRESENIUS KABI & $8025-2$ & 0.85 euros & 2 & 1.70 euros \\
\hline \multicolumn{6}{|l|}{ Daily calibration } \\
\hline Empty bag $(100 \mathrm{~mL})$ & MACOPHARMA & YZG0219EU & 2.7 euros & 1 & 2.7 euros \\
\hline Syringe $(60 \mathrm{~mL})$ & $\mathrm{BD}$ & 300865 & 0.22 euros & 2 & 0.44 euros \\
\hline Female coupling & $\mathrm{ICU}$ & 011-DC & 0.576 euros & 2 & 1.152 euros \\
\hline Spike ${ }^{\circledR}$ & ICU & $\mathrm{CH}-70$ & 1.31 euros & 10 & 13.1 euros \\
\hline
\end{tabular}

administered by a single Repeater ${ }^{\circledR}$ pump at different flow rates and for volumes ranging from 10 to $250 \mathrm{~mL}$. Between each series/set of measurement, a calibration of the pump was performed with a calibration volume of $40 \mathrm{~mL}$. For the pump flow rate of "Medium 5", the total error was between 1 and $3 \%$ with coefficients of variation of less than $1 \%$.

The analysis confirmed our method for pump calibration, which consisted on the visual reading of a $40 \mathrm{~mL}$ injection volume syringes. This one-time calibration method before the start of the activity ensured the accuracy of volumes injected throughout the day.

The time gained in the preparation by the use of pumps was evaluated by comparing the time of manual preparation and automated preparation over a total of 48 time measurements. With the automated procedure, over $2 \mathrm{~min}$ per preparation were gained. Parameters such as the preparation of the reservoir bags and of the assembly were not measured since their impact on the preparation time could not be estimated. Nevertheless, the important saving of time will make it possible to reduce the waiting time of the patient when the assembly will be used in routine.

The decrease in the risk of MSD occurrence through the automation of the preparation was confirmed by the third part of this study. Pharmacy technicians completed a self- assessment questionnaire on the risk of MSD occurring after manual and automated preparation. The repeatability of gestures, the manual effort, the physical posture constraints of the shoulders, forearms, wrists and fingers and the skin overpressure were significantly diminished by the automation of the preparations. Only the decrease in neck posture constraints was not significant based on statistical analyses. Other teams have used the motorization of infusion pumps with the aim of minimizing the risk of MSDs [24-28]. Bourget et al. developed a motorized apparatus able to suppress the risk of MSDs caused by the manual filling of portable infusion pumps [24]. However, the impact of the automation on MSDs was not evaluated as part of the study.

Despite these advantages, some limitations could be identified: during the installation, a stage is particularly risky. Indeed, the risk of connecting the reservoir bag filled with 5-FU to the pump identified as "diluent" and connecting the reservoir bag of $0.9 \% \mathrm{NaCl}$ to the pump identified as " 5 -FU" could have serious consequences. This risk is however limited by the double control of the assembly imposed in the procedure. In addition, the risk of injecting the wrong volume was limited by gravimetric system implemented in our center that detects volume errors at $5 \%$ of the theoretical volume. 
Second, the calibration of the pumps before use strongly impacts on the accuracy of the volumes [29, 30]. The calibrations of the pumps are performed by visual reading of the syringe.

This method is more or less precise and remains dependent on the user performing the calibration, which implies an adapted and rigorous training of the staff. Improper calibration increases the risk of error in the administered volumes. However, the risk of injection of a volume too small or too large is limited, since our gravimetric system detects volume errors at more or less $5 \%$ of the theoretical volume [31].

Last, the automation of the preparation generates and additional cost of $70.44 €$ (including all taxes) if only one preparation is made during the day, the cost of assembly having a strong impact on the total cost. However, this extra cost of preparation, mainly due to the price of the material, decreases with an increase of the number of preparations carried out daily to reach $2.44 €$ (including all taxes) for 10 preparations, thus allowing to even the price of the assembly. On the other hand, the economic evaluation was carried out on the current market prices. When the automation of the preparations is used routinely, price can be negotiated in view of the increase in the use of consumables.

In addition, the cost of acquiring pumps is still affordable compared to other more expensive and cumbersome automated assemblies that sometimes require a rearrangement within the unit that generates additional costs.

The filling system developed by our unit therefore responds to the objectives of saving time and of decreasing the risk of MSD occurrence while remaining accurate on the volumes injected. The assembly is fully compatible with our gravimetric control system and ensures a safety level equivalent to that achieved with a manual preparation. Finally, the economic study shows that the additional cost generated by the automation of the preparations can be evened by considering the number of preparations made by our unit (average of $105-\mathrm{FU}$ elastomeric pumps per day).

Research funding: None declared.

Author contributions: All authors have accepted responsibility for the entire content of this manuscript and approved its submission.

Competing interests: Authors state no conflict of interest. Informed consent: Informed consent was obtained from all individuals included in this study.

Ethical approval: The local Institutional Review Board deemed the study exempt from review.

\section{References}

1. White R, Cassano-Piché A, Fields A, Cheng R, Easty A. Intravenous chemotherapy preparation errors: patient safety risks identified in a pan-Canadian exploratory study. J Oncol Pharm Pract 2014; 20:40-6.

2. Limat S, Drouhin JP, Demesmay K, Tissot E, Jacquet M, WoronoffLemsi MC. Incidence and risk factors of preparation errors in a centralized cytotoxic preparation unit. Pharm World Sci 2001;23: 102-6.

3. Sarfati L, Ranchon F, Vantard N, Schwiertz V, Gauthier N, He S, et al. SIMMEON-Prep study: simulation of medication errors in oncology: prevention of antineoplastic preparation errors. J Clin Pharm Ther 2015;40:55-62.

4. Phillips J, Beam S, Brinker A, Holquist C, Honig P, Lee LY, et al. Retrospective analysis of mortalities associated with medication errors. Am J Health Syst Pharm 2001;58:1835-41.

5. Bateman R, Donyai P. Errors associated with the preparation of aseptic products in UK hospital pharmacies: lessons from the national aseptic error reporting scheme. Qual Saf Health Care 2010;19:e29.

6. Taxis K, Barber N. Ethnographic study of incidence and severity of intravenous drug errors. BMJ 2003;326:684.

7. Le Grognec C, Lazzarotti A, Marie-Joseph DA, Lorcerie B. Medication errors resulting from drug preparation and administration. Therapie 2005;60:391-9.

8. Carrez L, Martin V, Verrey AS, Furrer P, Bouchoud L, Falaschi L, et al. Qualification and performance evaluation of an automated system for compounding injectable cytotoxic drugs. Pharm Technol Hosp Pharm 2018;3:165-75.

9. Sabbagh Dit Hawasli Racha. Ambulatory chemotherapy: what community and hospital pharmacists need to know. Kingston University London; 2015. p. 30.

10. Baxter. Baxter elastomeric pumps. In: Clinicians Guide. Available from: https://www.capca.ca/wp-content/uploads/BaxterElastomeric-Pumps-Clinician-Guide11.pdf.

11. Duquesne J, Lamberdiere AL, Rousseau C, Yav F, baylatry MT, Joly AC. Évaluation de l'utilisation de la pompe Baxa Repeater ${ }^{\circledR}$ pour la préparation de diffuseurs de chimiothérapie. Pharm Hosp Clin 2012;47:291.

12. Ouali H, Bonnabry P, Widmer N, Blatrie C. Analyse et amélioration de la sécurité de la préparation et de l'administration des chimiothérapies par une analyse prospective des risques. Pharm Hosp Clin 2017;52:e34.

13. Roch C, Martelli N, Vernois J, Pradeau D, Caudron E. Evaluation of physical constraints related to the use of medical devices during the cytotoxic compounding. In: GERPAC Conference, France; 2015. Available from: https://www.gerpac.eu/evaluation-ofphysical-constraints-related-to-the-use-of-medical-devicesduring-the-cytotoxic-compounding.

14. Sankhare D, Bardo P, Bisseux L, Batistella M, Benassaia L, Bellenger $P$, et al. Utilisation optimale de la pompe péristaltique BAXA REPEAT $®$ pour la fabrication de lots de préparations hospitalières. Pharm Hosp Clin 2012;47:278.

15. Grimaux J, Guedon A, Gauthier Villano L, Bertault Peres P, Pourroy B. Implementation of an automated production system in assistance Publique Hopitaux de Marseille Anticancer Drugs Production Units: a feasibility study. In: GERPAC Conference, France; 2017. Available from: https://www.gerpac.eu/ 
implementation-of-an-automated-production-system-inassistance-publique-hopitaux-de-marseille-anticancer-drugsproduction-units-a-feasibility-study.

16. Caffin AG, Vazquez R, Guerrault-Moro, Brossard D, CrausteManciet S. Advantages of using a peristaltic pump for dose banding of cytotoxic drugs. IN: GERPAC Conference, France; 2017. Available from: https://www.gerpac.eu/advantages-of-using-aperistaltic-pump-for-dose-banding-of-cytotoxic-drugs.

17. Villain A, Feutry F, Bogart E, Villain J, Sakji I, Marliot G. Automated preparation of $5 \mathrm{FU}$ elastomeric pump. Impact on Repetitive Strain Injury risk and preparation time. In: GERPAC Conference, France; 2018. Available from: https://www.gerpac.eu/automatedpreparation-of-5fu-elastomeric-pump-impact-on-repetitivestrain-injury-risk-and-preparation-time.

18. National Institute for Occupational Safety and Health. Ocupational Safety and Health Administration - Ergonomics. Available from: https://www.osha.gov/pls/oshaweb/owadisp. show_document?p_id=166\&p_table=TESTIMONIES.

19. Caffin AG, Vasquez R, Guerrault-Moro MN, Brossard D, Crauste-Manciet S. Advantages of using a peristaltic pump for dose banding of cytotoxic drugs. In: GERPAC Conference, France; 2011. Available from: https://www.gerpac.eu/ advantages-of-using-a-peristaltic-pump-for-dose-banding-ofcytotoxic-drugs.

20. Humbert M. Automatisation de la production anticipée de doses standardisées d'anticancéreux au CHR Metz-Thionville: étude pilote sur les diffuseurs de 5 -Fluorouracile et les pompes d'oxaliplatine et comparaison de deux pompes semiautomatiques. Thèse 2016.

21. Gass-Jegu F, Rigo Adrover M, Gairard-Dory A. Evaluation of the advantages to be derived from automating injectable hospital preparations of paediatric synges and analgesia bags. In: GERPAC Conference, France; 2011. Available from: https://www. gerpac.eu/evaluation-of-the-advantages-to-be-derived-fromautomating-injectable-hospital-preparations-of-paediatricsynges-and-analgesia-bags.

22. Garcés M, Vazquez R, Guerrault-Moro MN, Durand A. Operational qualification of an automated compounding device of parenteral nutrition: Medimix $®$ IMF. In: GERPAC Conference, France; 2015. Available from: https://www.gerpac.eu/operational- qualification-of-an-automated-compounding-device-ofparenteral-nutrition-medimix-r-imf.

23. Heloury J, Bouguéon G, Deljehier T, Jourand A, Berroneau A, Crauste-Manciet $\mathrm{S}$. Automation of aseptic sterile preparation: risk analysis and productivity comparison with manual process. Pharm Technol Hosp Pharm 2019;4:15-28.

24. Bourget P, Amin A, Loeuillet R, Tavares L, Violain C, Thromas N, et al. Design and development of a user-friendly motorized apparatus for the filling of portable infusion pumps by hospital and homecare health workers. Pharm Technol Hosp Pharm 2016;1:21-8.

25. Reisz F, Gairard-Dory A, Fonmartin K, Bourbon J, Gourieux B. Prevention of work related musculoskeletal disorders in pharmaceutical technology. In: GERPAC Conference, France; 2016. Available from: https://www.gerpac.eu/prevention-of-workrelated-musculoskeletal-disorders-in-pharmaceutical-technology.

26. Moine M, Ménard C, Sankhare D, Ventroux G, Breteau V, Faure P, et al. Manual or semi-automatic small batch preparation of chemotherapy: witch process is choose by the team? In: GERPAC. Available from: https://www.gerpac.eu/manual-or-semiautomatic-small-batch-preparation-of-chemotherapy-witchprocess-is-choose-by-the-team.

27. Goiffon E, Bayle J, Chevrier R. Automation of dose banded chemotherapy preparation: satisfaction survey on two automats. In: GERPAC Conference, France; 2017. Available from: https:// www.gerpac.eu/automation-of-dose-banded-chemotherapypreparation-satisfaction-survey-on-two-automats.

28. McLeod M, Zochowska A, Leonard D, Crow M, Jacklin A, Franklin BD. Comparing the upper limb disorder risks associated with manual and automated cytotoxic compounding: a pilot study. Eur J Hosp Pharm Sci Pract 2012;19:293-8.

29. Theodorides AA. Analysis of flow rate through elastomeric local infiltration alalgesia pumps. EC Orthop 2017;61:3-14.

30. Skryabina EA, Dunn TS. Disposable infusion pumps. Am. J. Health-Syst. Pharm. AJHP Off J Am Soc Health-Syst Pharm 2006; 63:1260-8.

31. Rousselle A, Bogart E, Dubreucq V, Villain A, Delbey S, Sakji I, et al. Gravimetric control: accuracy, stability and performances in routine mode. In: GERPAC Conference, France; 2017. Available from: https://www.gerpac.eu/gravimetric-control-accuracystability-and-performances-in-routine-mode. 